\title{
Optimizing Mechanical Insufflation-Exsufflation - Much More than Cough Peak Flow
}

Mechanical insufflation-exsufflation (MI-E) was introduced in the early 1950s by Barach, Beck, Bickerman, and colleagues ${ }^{1-7}$ as a method for improving cough in patients with neuromuscular weakness, respiratory disease, and retained pulmonary secretions. Their work reported enhanced secretion clearance, resolution of atelectasis, and significant increases in cough peak flow with few reported side effects. In one of these trials, MI-E was used to remove foreign bodies from the respiratory tract of anesthetized animals. ${ }^{7}$ All of these early studies used the exsufflation with negative pressure device manufactured by OEM Corporation (Norwalk, Connecticut) (Fig. 1). ${ }^{8}$ In the 1960s, with the adoption of tracheal intubation, airway suctioning, and invasive positive-pressure ventilation, the exsufflation with negative pressure device was effectively displaced from clinical use.

The development of a number of respiratory therapy techniques can be attributed to Barach, whose research observations and studies are classic physiology experiments. As early as 1953, Barach noted the importance of cough peak flow in identifying patients who might benefit from MI-E and for monitoring MI-E success. Given Barach's "the devil is in the details" approach, he performed studies evaluating the impact of varying insufflation and exsufflation pressures on the exhaled tidal volume and expiratory flow (Fig. 2). In this single subject, the differences in insufflation and exsufflation pressures were varied from 20 to $0 \mathrm{~cm} \mathrm{H}_{2} \mathrm{O}$. Volume delivered and peak expiratory flow were a function of the insufflation pressure and the pressure differential. For the time, these findings set the precedent for MI-E use. In the early 1980s, Bach ${ }^{9}$ resurrected the use of MI-E in patients with neuromuscular weakness and, relying heavily on the work by Barach 30 years earlier, detailed the importance of using cough peak flow to select patients for MI-E therapy and monitor

Mr Branson discloses relationships with Aerogen, Philips, and Ventec Life Systems. Dr Benditt discloses a relationship with Ventec Life Systems.

Correspondence: Richard D Branson MSc RRT FAARC, 231 Albert Sabin Way, Cincinnati OH 45267-0558. E-mail: richard.branson@uc.edu.

DOI: $10.4187 /$ respcare. 07682 success. The use of a cough peak flow $<160 \mathrm{~L} / \mathrm{min}$ as an indication for MI-E can be traced to this work.

In this month's Journal, Chatwin and Simonds ${ }^{10}$ provide evidence from a 4-y study of MI-E in 181 subjects with neuromuscular weakness. Their work is observational and reports the settings used by subjects with a variety of diagnosed disorders, predominantly neuromuscular. This work provides some much-needed data regarding MI-E use, success, and adherence in daily clinical practice. Chatwin and Simonds ${ }^{10}$ report that, on average, exsufflation pressures were greater than insufflation pressures by approximately $10 \mathrm{~cm} \mathrm{H}_{2} \mathrm{O}$, insufflation time was shorter than exsufflation

\section{See the Original Study on Page 135}

time, and the inspiratory flow profile was set to "high" in all subjects. Perhaps most important, they note that there was no correlation between cough peak flow and either insufflation or exsufflation pressures. This longitudinal study provides a view of the current application of MI-E at their highly experienced institution and provides a baseline upon which future work can advance the efficacy of this therapy. ${ }^{10}$ Whether the settings reported are optimal for secretion clearance cannot be determined due to the study design.

Insufflation-exsufflation pressures and rise time or inspiratory flow settings during MI-E therapy have not undergone the same scrutiny afforded ventilator settings and other parameters related to ventilatory care. Two sentinel outcomes in the last decade suggest that setting MI-E pressures is more complex than achieving a desired cough peak flow. The first is the observation by Andersen and colleagues ${ }^{11-12}$ regarding laryngeal collapse in subjects with bulbar involvement and amyotrophic lateral sclerosis (ALS). The second is the too-often overlooked work by Volpe and co-workers ${ }^{14-16}$ regarding the importance of an expiratory flow bias on secretion movement during MI-E and mechanical ventilation.

The larynx is a complex valve that modulates and safeguards the lower airway from aspiration. ${ }^{12}$ Germane to this discussion, the role of the larynx in normal cough is critical. Andersen and colleagues ${ }^{15-17}$ reported that, in subjects with ALS with bulbar involvement, the high 


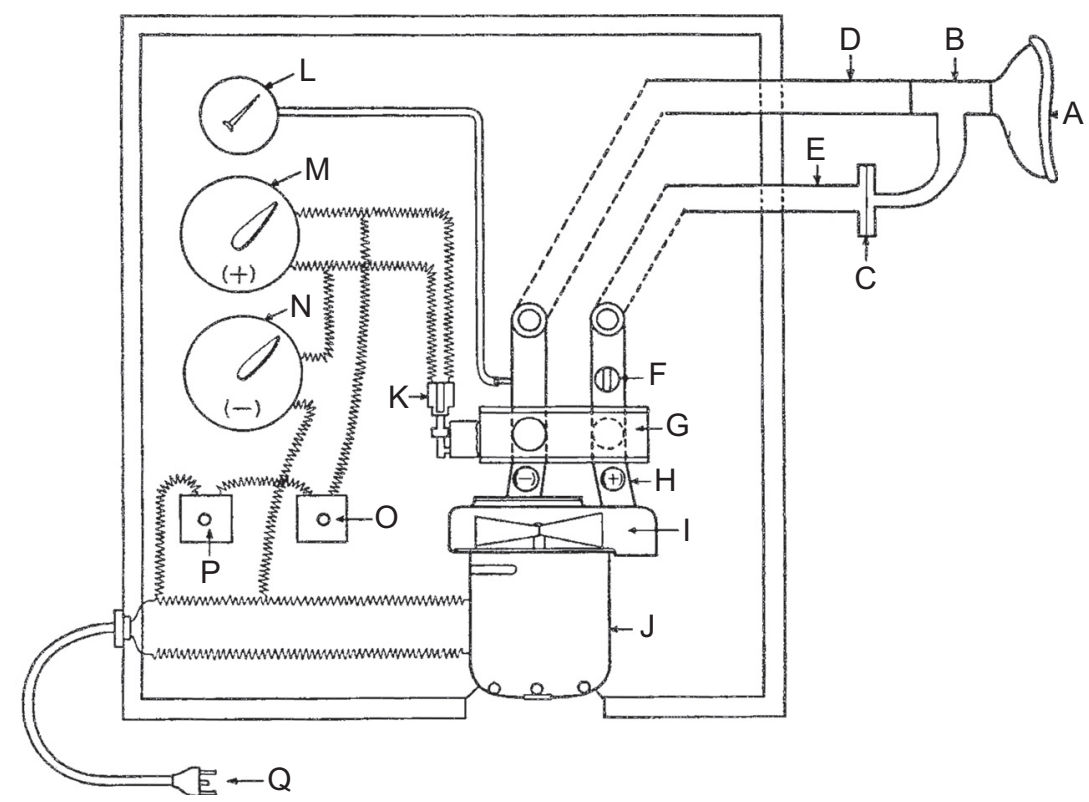

Fig. 1. Diagram of the OEM Cofflator. During the inspiratory phase, the fan (I) blows air through the valve (G), tubing (E), and the bacterial filter (C) to the mask $(A)$, which is placed over the patients face. The time of inspiration is controlled by the delay switch (M), the pressure is controlled by the relief valve $(\mathrm{H})$, and the volume delivered to the patient is controlled by the butterfly valve $(\mathrm{F})$. At the peak of inspiration, the solenoid $(\mathrm{K})$ rotates the valve $(G)$ so that the fan $(I)$ of the motor blower unit $(J)$ is swiftly connect to the tube $(D)$, which is connected with the mask $(A)$ through the T-piece (B) to the patient, producing a pressure drop of $60-80 \mathrm{~mm} \mathrm{Hg}$ in $0.02 \mathrm{~s}$. The motor and rotating valve are independently turned on by switches $(P)$ and $(O)$, respectively, and powered $(Q)$. From Reference 8.
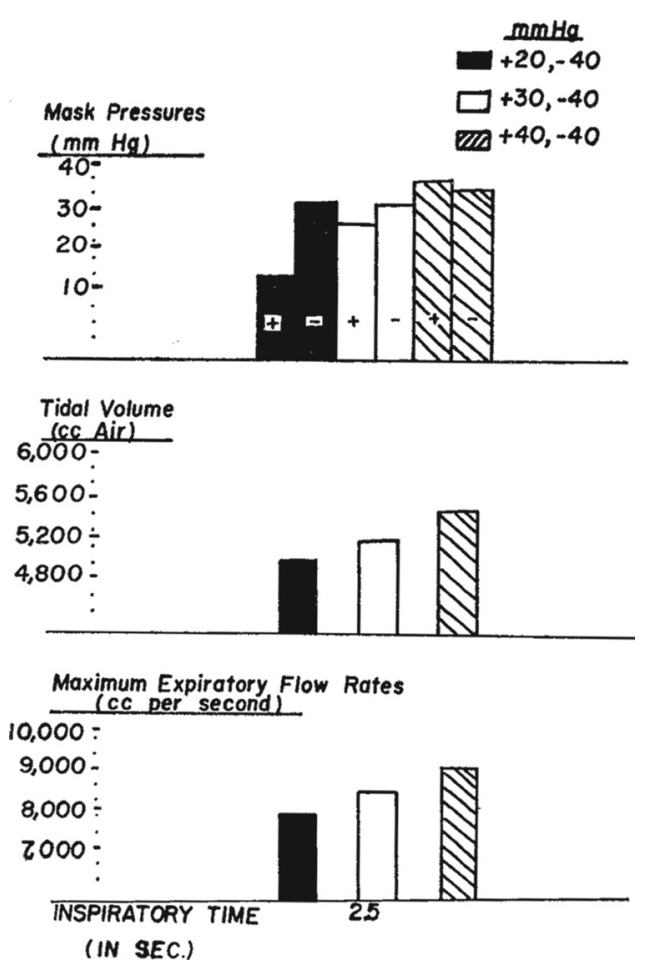

Fig. 2. Changes in tidal volume and expiratory flow during mechanical insufflation-exsufflation at varying insufflation-exsufflation pressures. From Reference 8. inspiratory pressures and rapid change from positive to negative expiratory pressure can alter laryngeal geometry. Using direct laryngoscopy in a number of elegant experiments, they observed vocal cord adduction and adduction of aryepiglottic folds at the highest positive pressure. ${ }^{15-17}$ They concluded that high insufflation pressures during MI-E in subjects with ALS can become counterproductive in disease progression, often prior to the onset of bulbar symptoms. They recommended that the application of positive inspiratory pressures should be tailored to the individual patient.

Lachal and others performed a bench study of MI-E using a model of a collapsible tube to represent the airway. ${ }^{17}$ They found that narrowing the collapsible tube, perhaps counterintuitively, increased cough peak flow. The appropriateness of this model and its ability to replicate the human physiology precludes any direct correlation. However, work by Lancombe et al $^{18}$ adds insight to these issues because they reported that cough peak flow failed to detect upper airway collapse during negative pressure titration of MI-E. They concluded that upper airway collapse was associated with an effective cough volume decrease and with increasing cough peak flow. ${ }^{18}$ Alternatively, the effective cough volume, but not cough peak flow, detected upper airway collapse. These data beg for further work on MI-E titration in different disease states.

Volpe et al ${ }^{14-16}$ have reported that the expiratory flow bias (ie, the difference between inspiratory and expiratory 

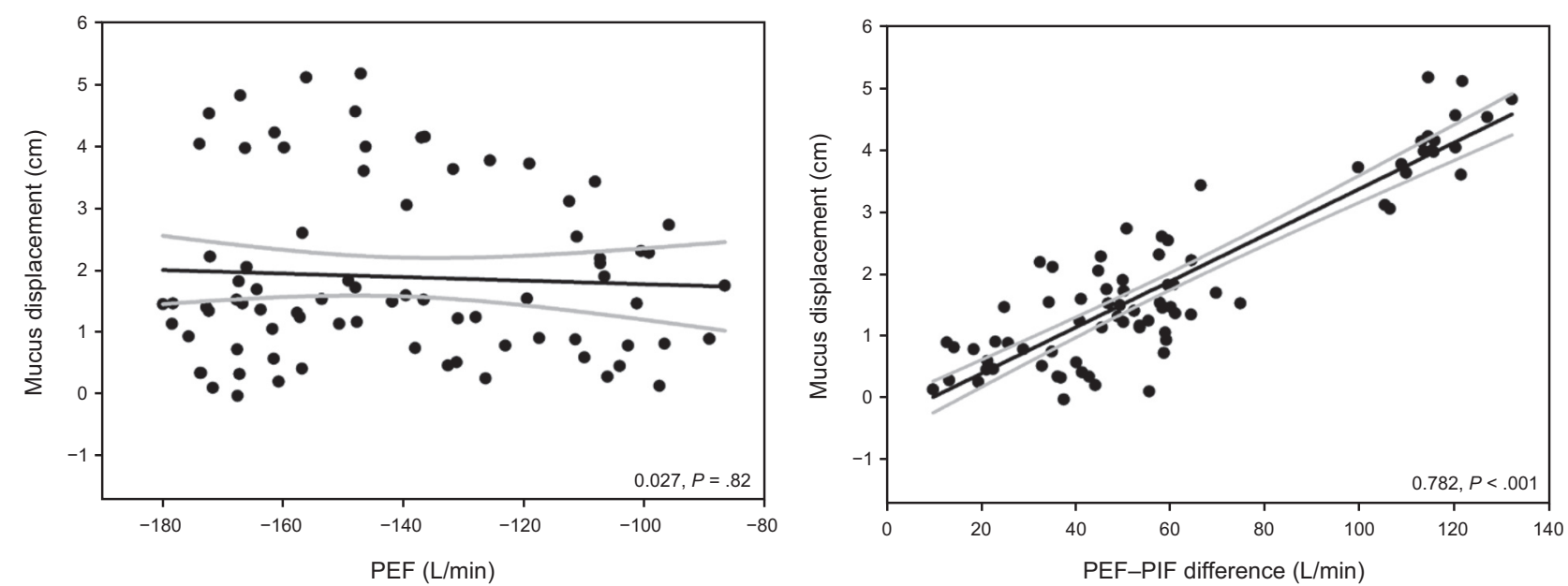

Fig. 3. Relationship of center-of-mass displacement to PEF - PIF difference and PEF. A negative displacement indicates mucus movement toward the test lung. Curve-fitting analysis is shown in black, with $95 \% \mathrm{Cl}$ in gray. PEF = peak expiratory flow; PIF = peak inspiratory flow. From Reference 16.

flow) is the key component of secretion movement during mechanical ventilation and MI-E. Flow bias creates mucus movement through 2-phase gas-liquid transport expressed as the ratio (PEF:PIF) or difference (PEF - PIF) between peak flows. Factors that affect mucus movement during 2phase gas-liquid transport include inspiratory-expiratory air velocity, mucus viscosity, and thickness of the mucus layer. The latter is an important issue; if the mucus layer is too thin relative to the airway lumen, secretion movement is more difficult. In their study of MI-E optimization, Volpe et $\mathrm{al}^{18}$ noted that the movement of artificial mucus in a tube was directly proportional to the expiratory flow bias and not the cough peak flow (Fig. 3). As with the work by Andersen et al, ${ }^{11-13}$ these careful experiments by Volpe and co-workers ${ }^{15,16}$ argue that the selection of MI-E settings should not be based on cough peak flow alone. In fact, the expiratory flow bias for secretion movement would favor a slow rise time (ie, low inspiratory flow), in opposition of the findings reported by Chatwin and Simonds. ${ }^{10}$ This is further supported by the work of Lancombe et al, ${ }^{19}$ which suggests that the time spent above a cough peak flow that causes secretion movement is more important than cough peak flow alone. This time-dependent component of MI-E has not been addressed adequately.

We applaud the work by Chatwin and Simonds ${ }^{10}$ because it establishes a state of the therapy of MI-E use. Further, we salute the pioneering work of Barach ${ }^{1-4}$ and are now influenced by the impressive new evidence provided by Andersen et $\mathrm{al}^{11-13}$ and Volpe et al. ${ }^{14-16}$ MI-E use is increasing in hospital and clinic settings, and we encourage researchers to further study optimum settings to promote secretion clearance, enhance patient safety, and prevent airway collapse.
Richard D Branson

Editor-in-Chief, RESPIRATORY CARE Department of Surgery, Division of Trauma \& Critical Care University of Cincinnati Cincinnati, Ohio

Joshua O Benditt

Department of Medicine University of Washington Medical Center Seattle, Washington

\section{REFERENCES}

1. Barach AL, Beck GJ, Bickerman HA. Physical methods simulating cough mechanisms: use in poliomyelitis, bronchial asthma, pulmonary edema and bronchiectasis. JAMA 1952;150(14):1380-1385.

2. Barach AL, Beck GJ, Bickerman HA, Seanor HE, Smith W. Physical methods simulating mechanisms of the human cough. J Appl Physiol 1952;5(2):85-91.

3. Barach AL, Beck GJ. Mechanical production of expiratory flow rates surpassing the capacity of human coughing. Am J Med Sci 1953;226 (3):241-249.

4. Barach AL. The application of pressure, including exsufflation, in pulmonary emphysema. Am J Surg 1955;89(2):372-382.

5. Beck GJ, Scarrone LA. Physiologic effects of exsufflation with negative pressure (EWNP). Dis Chest 1956;29(1):80-95.

6. Beck GL, Graham GC, Barach AL. Effect of physical methods on the mechanics of breathing in poliomyelitis. Ann Intern Med 1955;43 (3):549-566.

7. Bickerman HA. Exsufflation with negative pressure (EWNP). Elimination of radiopaque material and foreign bodies from bronchi of anesthetized dogs. Ama Arch Intern Med 1954;93(5):698-704.

8. Beck GJ. Methods of aiding bronchial drainage in pulmonary emphysema. In: Barach AL, Bickerman HA, editors. Pulmonary emphysema. Baltimore: Williams \& Wilkins; 1956:173-217.

9. Bach JR. Mechanical insufflation-exsufflation: comparison of peak expiratory flows with manual assisted and unassisted coughing techniques. Chest 1993;104(5):1553-1562. 


\section{EdITORIAL ON OPTIMIZING MECHANICAL INSUFFLATION-EXSUFFLATION}

10. Chatwin M, Simonds AK. Long-term mechanical insufflation-exsufflation cough assistance in neuromuscular disease: patterns of use and lessons for application. Respir Care 2020;65(2):135-143.

11. Andersen T, Sandnes A, Brekka AK, Hilland M, Clemm H, Fondenes $\mathrm{O}$, et al. Laryngeal response patterns influence the efficacy of mechanical assisted cough in amyotrophic lateral sclerosis. Thorax 2017;72 (3):221-229.

12. Andersen TM, Halvorsen T, Fondenes O, Heimdal J-H, Røksund OD, Vollsæter M, Røksund OD. Larynx: the complex gateway to the lungs. Respir Care 2019;64(7):866-869.

13. Andersen TM, Sandnes A, Fondenes O, Nilsen RM, Tysnes O-B, Heimdal J-H, et al. Laryngeal responses to mechanically assisted cough in progressing amyotrophic lateral sclerosis. Respir Care 2018;63(5):538-549.

14. Volpe MS, Adams AB, Amato MB, Marini JJ. Ventilation patterns influence airway secretion movement. Respir Care 2008;53(10):12871294.
15. Volpe MS, Nakamura MAM, Amato M. Comment on: effect of inspiratory rise time on sputum movement during ventilator hyperinflation in a test lung model. Physiotherapy 2019;105(2):293-294.

16. Volpe MS, Naves JM, Ribeiro GG, Ruas G, Amato M. Airway clearance with an optimized mechanical insufflation-exsufflation maneuver. Respir Care 2018;63(10):1214-1222.

17. Lachal R, Louis B, Subtil F, Guérin C. Bench assessment of the effect of a collapsible tube on the efficiency of a mechanical insufflationexsufflation device. Respir Care 2019;64(7):752-759.

18. Lacombe M, Boré A, Amo Castrillo LD, Boussaïd G, Falaize L, Vlachos E, et al. Peak cough flow fails to detect upper airway collapse during negative pressure titration for cough-assist. Arch Phys Med Rehabil 2019;100(12):2346-2353.

19. Lacombe M, Del Amo Castrillo L, Boré A, Chapeau D, Horvat E, Vaugier I, et al. Comparison of three cough-augmentation techniques in neuromuscular patients: mechanical insufflation combined with manually assisted cough, insufflation-exsufflation alone and insufflation-exsufflation combined with manually assisted cough. Respiration 2014;88(3):215-222. 